\title{
New Treatment Options for Osteosarcoma - Inactivation of Osteosarcoma Cells by Cold Atmospheric Plasma
}

\author{
DENIS GÜMBEL ${ }^{1,2^{*}}$, NADINE GELBRICH ${ }^{1 *}$, MARTIN WEISS $^{3}$, MATTHIAS NAPP ${ }^{1}$, \\ GEORG DAESCHLEIN ${ }^{4}$, AXEL SCKELL $^{1}$, STEPHAN A. ENDER $^{5}$, AXEL KRAMER ${ }^{6}$, \\ MARTIN BURCHARDT ${ }^{3}$, AXEL EKKERNKAMP ${ }^{1,2}$ and MATTHIAS B. STOPE $^{3}$ \\ Departments of ${ }^{I}$ Trauma, Reconstructive Surgery and Rehabilitation Medicine, \\ ${ }^{3}$ Urology, ${ }^{4}$ Dermatology, ${ }^{5}$ Orthopaedics and Orthopaedic Surgery, \\ ${ }^{6}$ Hygiene and Environmental Medicine, University of Medicine Greifswald, Greifswald, Germany; \\ ${ }^{2}$ Department of Trauma and Orthopaedic Surgery, \\ BG Klinikum Unfallkrankenhaus Berlin gGmbH, Berlin, Germany
}

\begin{abstract}
Background/Aim: Cold atmospheric plasma has been shown to inhibit tumor cell growth and induce tumor cell death. The aim of the study was to investigate the effects of cold atmospheric plasma treatment on proliferation of human osteosarcoma cells and to characterize the underlying cellular mechanisms. Materials and Methods: Human osteosarcoma cells (U2-OS and MNNG/HOS) were treated with cold atmospheric plasma and seeded in culture plates. Cell proliferation, $p 53$ and phospho-p53 protein expression and nuclear morphology were assessed. Results: The treated human osteosarcoma cell lines exhibited attenuated proliferation rates by up to $66 \%$. The cells revealed an induction of p53, as well as phospho-p53 expression, by 2.3fold and 4.5-fold, respectively, compared to controls. 4',6diamidino-2-phenylindole staining demonstrated apoptotic nuclear condensation following cold atmospheric plasma treatment. Conclusion: Cold atmospheric plasma treatment significantly attenuated cell proliferation in a preclinical in vitro osteosarcoma model. The resulting increase in p53 expression and phospho-activation in combination with characteristic nuclear changes indicate this was through induction of apoptosis.
\end{abstract}

\footnotetext{
*These Authors contributed equally to this study.

Correspondence to: Dr. Denis Gümbel, M, Department of Trauma, Reconstructive Surgery and Rehabilitation Medicine, University Medicine Greifswald, Ferdinand-Sauerbruch-Straße, 17475 Greifswald, Germany. Tel: +49 038348622541, Fax: +49 038348622215, e-mail: denis.guembel@uni-greifswald.de
}

Key Words: Osteosarcoma cell culture, cold atmospheric plasma, antitumor efficacy, activation of $p 53$ gene, apoptosis.
Plasma, the fourth state of matter, can be subdivided into thermal, and non-thermal, so-called cold atmospheric plasma (CAP) (1). Thermal plasma has a temperature of more than $10,000^{\circ} \mathrm{C}$. Its clinical applications include the ablation of tumors or coagulation of blood vessels due to its high temperature and consequent alteration of molecular structures during treatment. CAP temperature ranges from $20^{\circ} \mathrm{C}$ to $50^{\circ} \mathrm{C}$, thus preserving molecular structures and cellular integrity. CAP can be described as a partially ionized gas generated by focused electric discharge. It contains a dose-controlled mixture of highly reactive and energetic particles, including positive and negative ions, electrons, excited atoms and molecules (i.e. singlet-oxygen), free radicals such as reactive oxygen (ROS) and nitrogen (RNS) species, characterized by atoms or molecules containing an unpaired electron, photons, and electromagnetic fields, leading to the emission of visible UV or VUV radiation. The reactive compounds, which become biochemically active, emerge either during the generation of the plasma in due course of the interaction with molecules of the surrounding air, or with the medium, bodily fluid, or tissue to be treated. In addition to direct plasma effects due to the composition of CAP at the effect site, there are also subsequent secondary actions within the tissue, based on radical formation by CAP, similarly to physiologically generated radicals.

CAP effects on living tissues have been shown to be profoundly caused by the interaction of a mixture of chemical reactive radicals and elementary particles with cell membrane structures and molecular signaling pathways. Most commonly used inert carrier gases for CAP are argon and helium (2).

CAP offers a broad spectrum of clinical applications, including eradication of pathogens (3), blood coagulation and treatment of chronic wounds (4). More recently, its anticancer effects have been discovered in vitro and in vivo and have led 
to establishment of a new medical field called plasma oncology (5). CAP has been shown to inhibit tumor cell growth, induce cell death and is more effective against tumor cells than normal non-neoplastic cells, making it a promising therapeutic option $(6,7)$. However, the underlying molecular mechanisms remain poorly understood (8). Temporary loss of cell adhesion and programmed cell death are two important cell responses that have been identified so far (6).

Osteosarcoma (OS) is the most common primary malignant bone tumor in adolescents and young adults. Multi-agent chemotherapy and improved surgical techniques have led to a long-term survival rate of up to $60-70 \%$ in localized non-metastatic disease of the extremities (9). The treatment strategy depends on the extent, location, and grade of the tumor, as well as patient factors including age and general condition. In cases where radical surgical en bloc resection cannot be achieved with conventional surgical techniques, additional treatment options are needed.

Due to its potential for tumor reduction and metastasis prevention, CAP treatment may be a promising new therapeutic approach to further improve outcomes of patients with OS. The purpose of this study was therefore to analyze the effects of CAP on human osteosarcoma cell lines U2-OS and MNNG/HOS and to further characterize cellular effects and underlying molecular mechanisms.

\section{Materials and Methods}

Cell culture. The human OS cell lines U2-OS and MNNG/HOS (purchased from the American Type Culture Collection, Manassas, VA, USA) were propagated in Dulbecco's modified Eagle's medium (DMEM) containing $1.0 \mathrm{~g} / \mathrm{l}$ glucose supplemented with $10 \%$ fetal bovine serum, $1 \mathrm{mM}$ sodium pyruvate, and $1 \%$ penicillin/ streptomycin (all from PAN Biotech, Aidenbach, Germany) at $37^{\circ} \mathrm{C}$ in a humidified atmosphere with $5 \% \mathrm{CO}_{2}$ atmosphere.

CAP treatment. For generation of CAP, the plasma jet kINPen MED (Neoplas Tools, Greifswald, Germany) was used (argon as carrier gas, gas flow: $3 \mathrm{l} / \mathrm{min}$; supply voltage $=65 \mathrm{~V} \mathrm{DC}$; frequency: 1.1 $\mathrm{MHz}$ ). For cell proliferation assessment after CAP treatment, $4.0 \times 10^{4}(\mathrm{U} 2-\mathrm{OS})$ and $8.0 \times 10^{4}(\mathrm{MNNG} / \mathrm{HOS})$ cells were suspended in $200 \mu \mathrm{l}$ DMEM on an uncoated 24-well cell culture plate and treated for $10 \mathrm{~s}$ with CAP or argon gas as control, respectively. After CAP treatment, cells were immediately transferred to poly-L-lysine (PAN Biotech) coated 24-well cell culture plates and incubated in DMEM for 4, 24, 48, 72, 96 and $120 \mathrm{~h}$. For protein analysis, $5.0 \times 10^{5}$ cells were suspended in $500 \mu \mathrm{DMEM}$, treated with CAP and incubated in poly-L-lysine coated 6-well cell culture plates.

Cell proliferation assay. Proliferation of U2-OS cells was examined by viable cell counting utilizing a CASY Cell Counter and Analyzer Model TT (Roche Applied Science, Mannheim, Germany). Therefore, cells were detached by trypsin treatment, suspended in CASYton (Roche Applied Science). A 1:100 dilution, and three replicates of $400 \mu \mathrm{l}$ of cell suspension were analyzed. Measurements were performed using a capillary of $150 \mu \mathrm{m}$ in diameter and cell line-specific gate settings to discriminate between viable and dead cells, and cellular debris: $7.20 \mu \mathrm{m} / 13.95 \mu \mathrm{m}$ for U2-OS cells, $7.20 \mu \mathrm{m} / 14.85 \mu \mathrm{m}$ for MNNG/HOS cells.

Western blotting. Cells were lysed [RIPA buffer: $50 \mathrm{mM}$ Tris ( $\mathrm{pH}$ 7.5), $150 \mathrm{mM} \mathrm{NaCl}, 10 \mathrm{mM} \mathrm{K} 2 \mathrm{HPO} 4,5 \mathrm{mM}$ EDTA, 10\% glycerol, $1 \%$ Triton $\mathrm{X}-100,0.05 \%$ sodium dodecysulfate, $1 \mathrm{mM} \mathrm{Na} \mathrm{VO}_{4}$, $20 \mathrm{mM} \mathrm{NaF}, 0.1 \mathrm{mM}$ phenylmethylsulfonyl fluoride, $20 \mathrm{mM}$ 2-phosphoglycerate, complete protease inhibitor cocktail from Roche Applied Science] and western blotting was performed using standard techniques as described elsewhere (10). Primary antibodies against p53, phospho-p53, and glyceraldehyde 3-phosphate dehydrogenase (GAPDH) were used in combination with the appropriate peroxidase-conjugated secondary antibody (all from Cell Signaling Technology, Danvers, MA, USA). Proteins were visualized using SuperSignal West Dura Chemiluminescent Substrate (Thermo Scientific, Waltham, MA, USA) in a ChemidocSystem (Biorad, Munich, Germany) and quantified using Image Lab 3.0 (Biorad) software according to the manufacturer's instructions.

Fluorescence microscopy. U2-OS cells were seeded onto $3.5-\mathrm{cm}$ cell culture dishes and incubated for $24 \mathrm{~h}$. For microscopic analysis, cells were washed with phosphate-buffered saline (PBS; PAN Biotech), fixed with $4 \%$ paraformaldehyde, rinsed twice with PBS and permeabilized using $0.2 \%$ Triton X-100 (Carl Roth GmbH + Co. KG, Karlsruhe, Germany). Subsequently, chromosomal nucleic acids were stained with 4',6-diamidino-2-phenylindole (DAPI; Carl Roth) and nucleus-specific signals were recorded using a BZ-9000 Fluorescent Microscope System (Keyence, Osaka, Japan).

Nuclear morphological assay. Characteristic changes of nuclear morphology that occur during apoptotic condensation include reduction in nuclear area and perimeter, nuclear deformation and unrounding. These morphological changes and are also referred to as nuclear shrinkage. For the detection of apoptotic changes in nuclear morphology, microscopic images of DAPI-stained cells were analyzed using a BZ II Analyzer software (Keyence). DAPI signals of $0.5 \%$ of the total growth area were recorded and subsequently analyzed regarding area, perimeter and brightness of nuclear staining as described elsewhere (11). DAPI-positive nuclei were defined by co-localization function of the Hybrid Cell Count BZ-H2C module defining a range from 0.3-200 $\mu \mathrm{m}^{2}$, thus excluding nuclear cluster and fragmented nuclei.

Statistical analysis. Statistical analysis was performed using GraphPad Prism 5.0 software (GraphPad Software, Inc., La Jolla, CA, USA). Data shown in the figures are either from representative experiments or expressed as the mean $\pm \mathrm{SD}$ of at least five independent experiments. Significant differences between experimental and control groups were determined using the unpaired Student's $t$-test. $p$-Values of 0.05 or less were considered statistically significant.

\section{Results}

CAP treatment of OS cells attenuates cellular growth rates in an in vitro cell culture model. To monitor a putative inhibitory effect of CAP on U2-OS cell proliferation, CAPtreated cells were cultivated over a period of $120 \mathrm{~h}$. Control treated U2-OS cells demonstrated characteristic cell growth, 

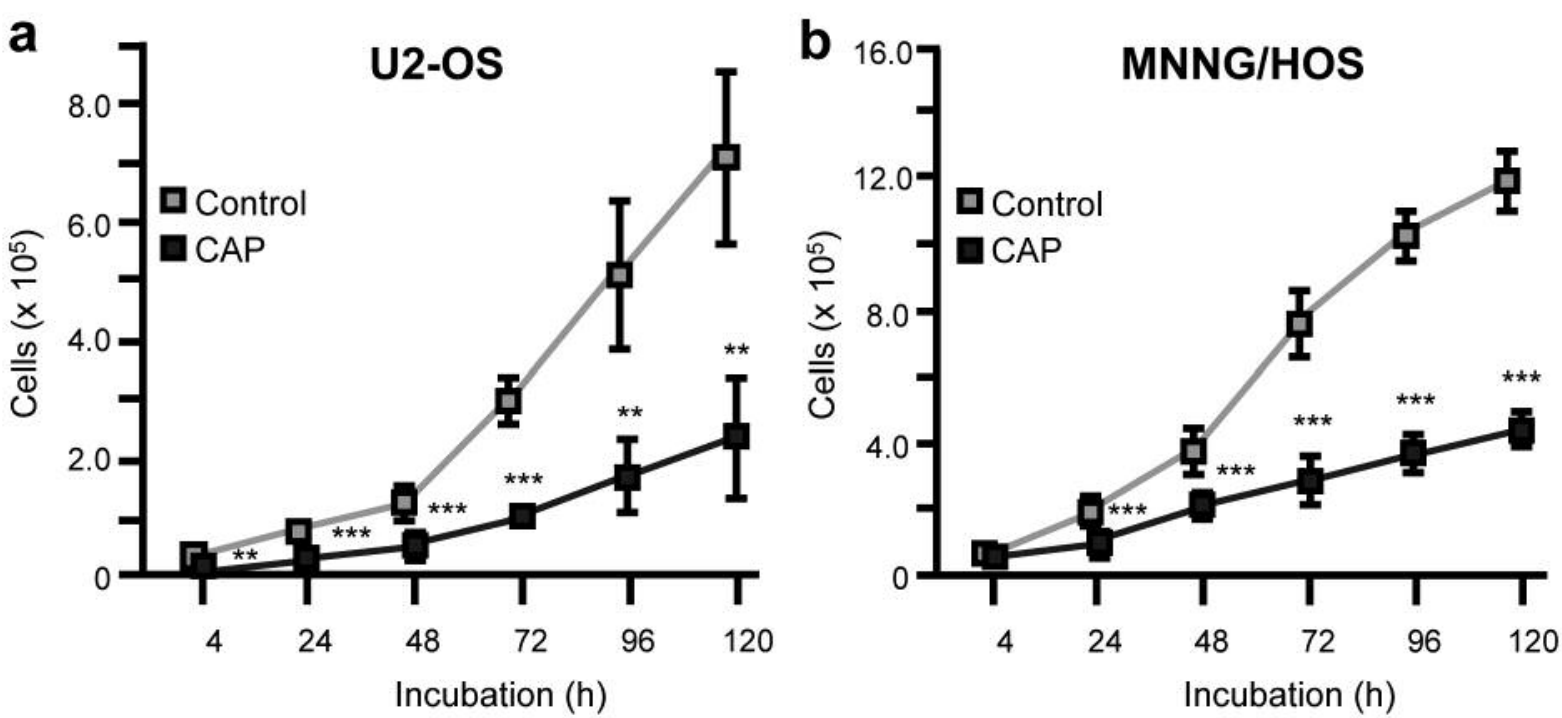

Figure 1. Growth-inhibitory properties of cold atmospheric plasma (CAP) in an in vitro cell culture model of osteosarcoma (OS). U2-OS cells (a) and MNNG/HOS cells $(b)$ were CAP-treated for $10 \mathrm{~s}$ and cell proliferation was assessed at different time points utilizing a CASY Cell Counter and Analyzer Model TT (Roche Applied Science). Data are given as the mean $\pm S D$, statistically analyzed by Student's t-test. Significantly different compared to the control at $* p \leq 0.05, * * p \leq 0.01$, and $* * * p \leq 0.001$.

whereas CAP treatment of U2-OS cells exhibited significantly attenuated proliferative rates (Figure 1a). Further incubation experiments applying MNNG/HOS cells confirmed these results. Compared to characteristic cell growth of control cells, CAP treatment led to significantly reduced proliferation of MNNG/HOS cells (Figure 1b).

CAP-induced attenuation of OS cells is paralleled by upregulation and activation of the apoptotic factor p53. p53 expression as a key regulator of apoptosis in mammalian cells after CAP treatment was examined. Western blot analysis of CAP-treated OS cells revealed significant induction of p53 expression in U2-OS cells compared to controls. Although no induction was detectable in MMNG/HOS cells (Figure 2b), phosphor-activation of the protein was found $24 \mathrm{~h}$ after CAP treatment (Figure $2 \mathrm{~d}$ and $\mathrm{f}$ ). In addition to induction of p53 expression, phosphorylation is also required for initiation of p53-dependent apoptosis pathways. Therefore, protein analysis utilizing phospho-p53-specific antibodies was performed. The phospho-p53 status in U2-OS cells as well as in MNNG/HOS cells indicated enhanced the activation of $\mathrm{p} 53$ protein following CAP treatment (Figure $2 \mathrm{c}$ and $\mathrm{d}$, respectively). Analysis of phospho-p53 relative to total p53 demonstrated activation of p53-dependent signaling pathways in U2-OS cells and MNNG/HOS cells in response to CAP treatment (Figure 2e and f, respectively).

Morphology of CAP-treated OS cells suggests apoptotic changes. DNA condensation and nuclear degradation are later events in apoptotic cell death. For this reason, nuclear morphology of CAP-treated cells was assessed. Light microscopic analysis $24 \mathrm{~h}$ after CAP treatment demonstrated morphological changes in both cell lines compared to controls (Figure 3). Accordingly, nuclear morphological characteristics were prominently altered in both U2-OS (Figure 3b and d) and MNNG/HOS (Figure 3f and h) cells compared to argon-treated cells, pointing to apoptotic nuclear degradation and apoptotic body formation.

In order to test this hypothesis, bioinformatic analyses including evaluation of apoptotic changes were performed. Fluorescence microscopic analysis of OS cell nuclei showed that CAP-treated cells formed shrunken nuclei demonstrated by reduced area (Figure $4 a$ and $b$ ). DAPI staining of OS cell nuclei yielded an increased brightness of CAP-treated cells indicating DNA condensation during apoptosis (Figue 4c).

\section{Discussion}

Being new in the field of medical applications of physical plasma, plasma oncology is an important new topic in healthcare $(4,5)$. Numerous studies have been carried out in in vitro and in in vivo cancer models demonstrating antineoplastic effects of CAP in solid tumors including prostate cancer, pancreatic cancer, malignant melanoma, and glioma $(5,6,12,13)$. OS therapy is complicated by the development of adverse effects that result from treatment with aggressive cytotoxic chemotherapeutic agents (9). Furthermore, therapy resistance of human osteosarcoma with poor prognosis has 

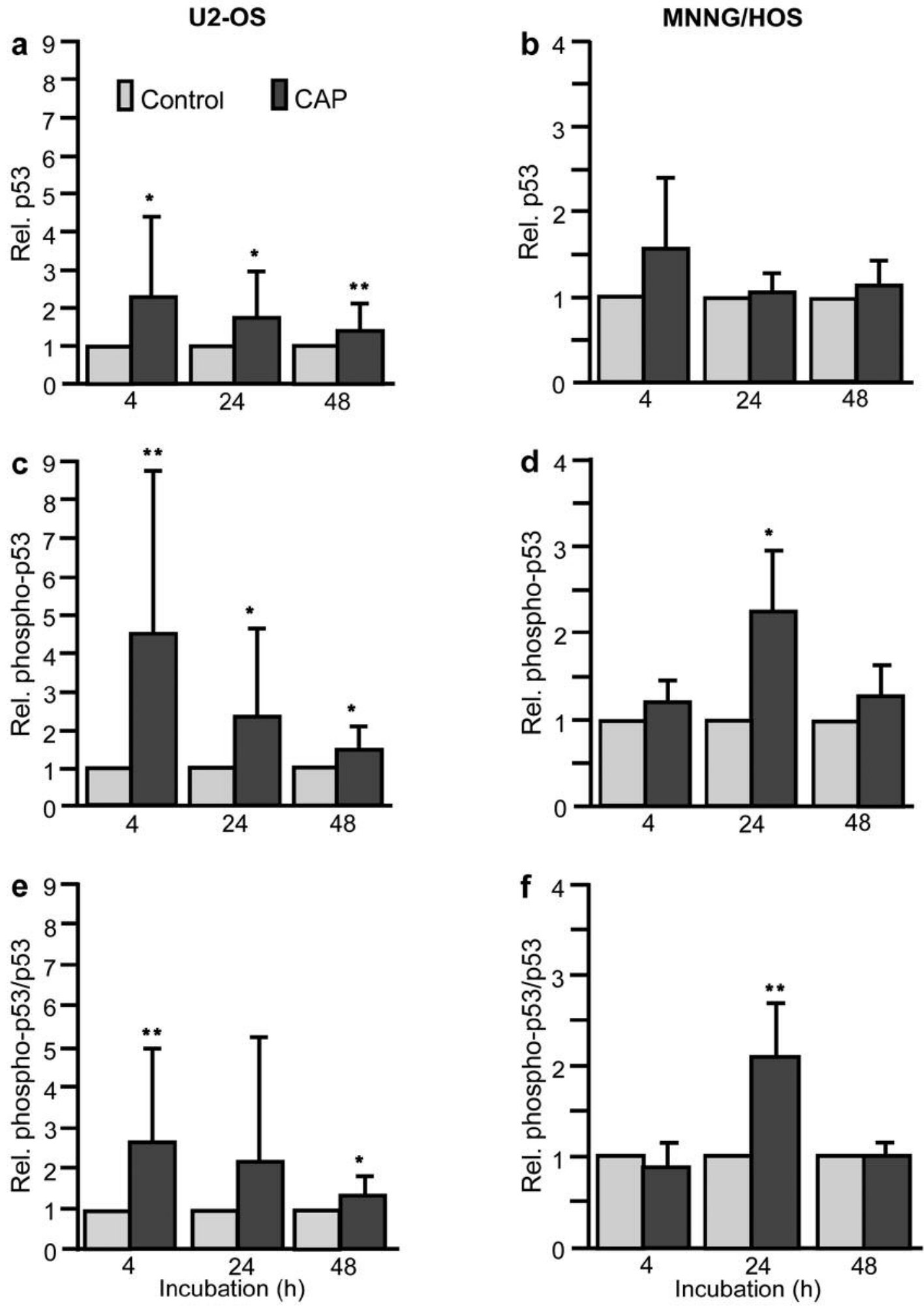

Figure 2. Cold atmospheric plasma (CAP)-induced expression and phospho-activation of the apoptotic regulator p53 in osteosarcoma (OS) cells. U2OS cells $(a, c, e)$ and MNNG/HOS cells $(b, d, f)$ were CAP-treated for $10 \mathrm{~s}$, incubated for the indicated times, and harvested cells were subjected to western blot analysis using antibodies directed against total p53 $(a, b)$ and phospho-p53 $(c, d)$. Glyceraldehyde 3-phosphate dehydrogenase $(G A P D H)$ signals served as loading control. Phosphorylation rate of $p 53$ was calculated by the phospho-p53/total p53 ratio (e,f). Data are given as the mean $\pm S D$, statistically analyzed by Student's $t$-test. Significantly different compared to the control at $* p \leq 0.05$ and $* * p \leq 0.01$. 

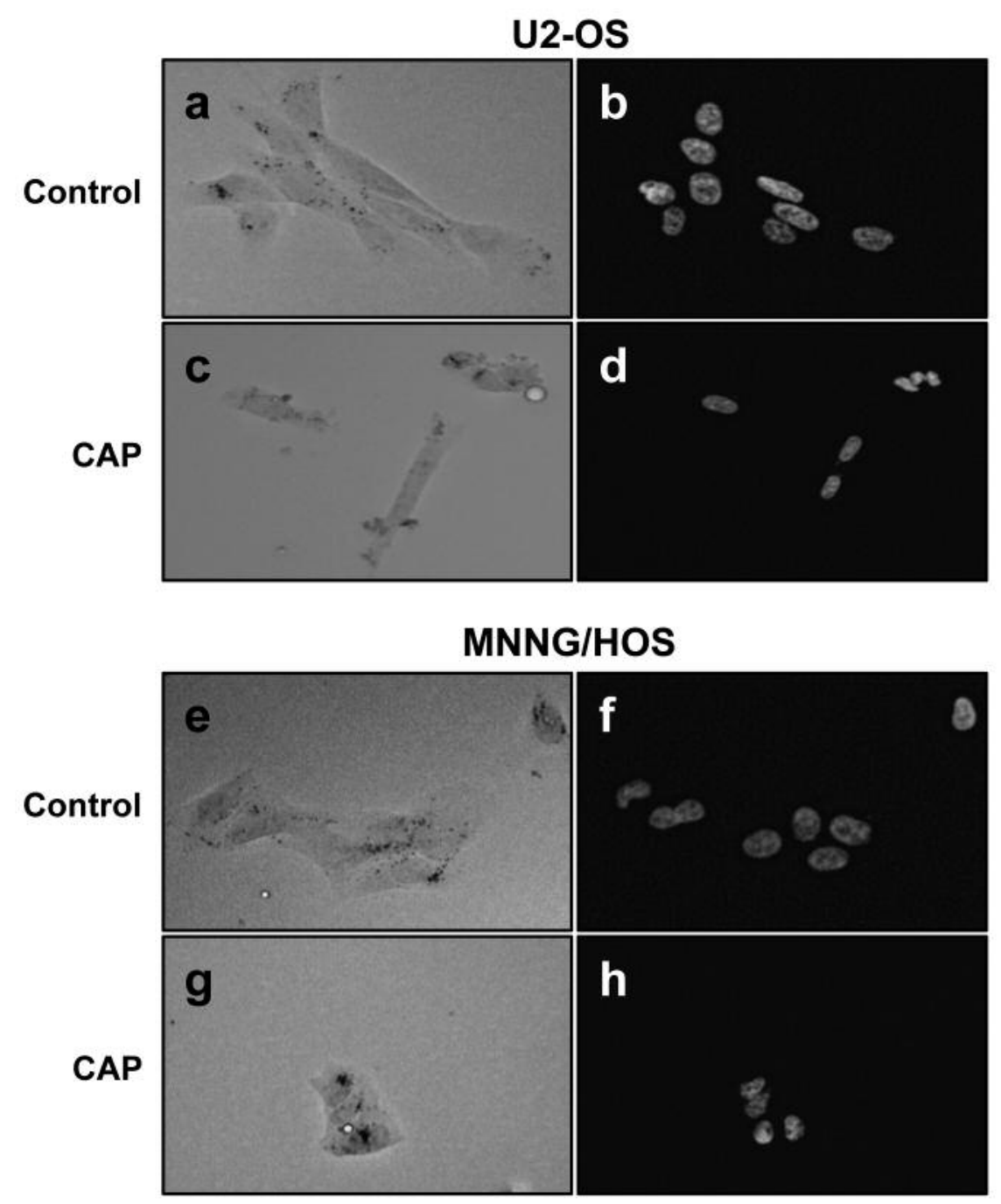

Figure 3. Cold atmospheric plasma (CAP)-induced apoptotic changes of cell and nuclear morphology. For light ( $a, c, e, g)$ and fluorescence ( $b, d$, $f, h)$ microscopy analysis, fixed U2-OS cells ( $a-d)$ and MNNG/HOS cells $(e-h)$ were characterized utilizing a BZ-9000 fluorescent microscope system (Keyence) at ×60 magnification. Nuclear-specific staining was performed using 4',6-diamidino-2-phenylindole stain.

been reported in certain patient subgroups, necessitating new therapeutic options $(14,15)$. Hence the present study evaluated for the first time the impact of CAP on the treatment of OS and found it a promising alternative therapeutic approach or favorable additional therapeutic option. By utilizing a preclinical in vitro OS model system (U2-OS cells, MNNG/HOS cells), we demonstrated that CAP treatment significantly attenuates cancer cell proliferation and that this effect is associated with apoptosis (Figure 5).

Performing a single CAP treatment of $10 \mathrm{~s}$ was sufficient to inactivate OS cells significantly. Notably, cell proliferation was apparently attenuated by p53-initiated apoptosis. In contrast to necrosis, apoptosis involves regulated enzyme activities of proteases and nucleases. Moreover, due to a nearly intact cytoplasmic membrane, apoptotic degradation is not associated with the liberation of critical biomolecules which may induce local or systemic processes of inflammation and immune responses (16). Induction of apoptosis by cytostatics is a common mode of action on the cellular level $(17,18)$ and has also been reported for OS anticancer drugs $(19,20)$. CAP-dependent induction of apoptosis has been demonstrated in malignant, as well as in non-malignant cells $(5,6,13,21,22,23)$.

Clinical application of CAP in OS therapy may involve radical computer-assisted surgical tumor resection and 

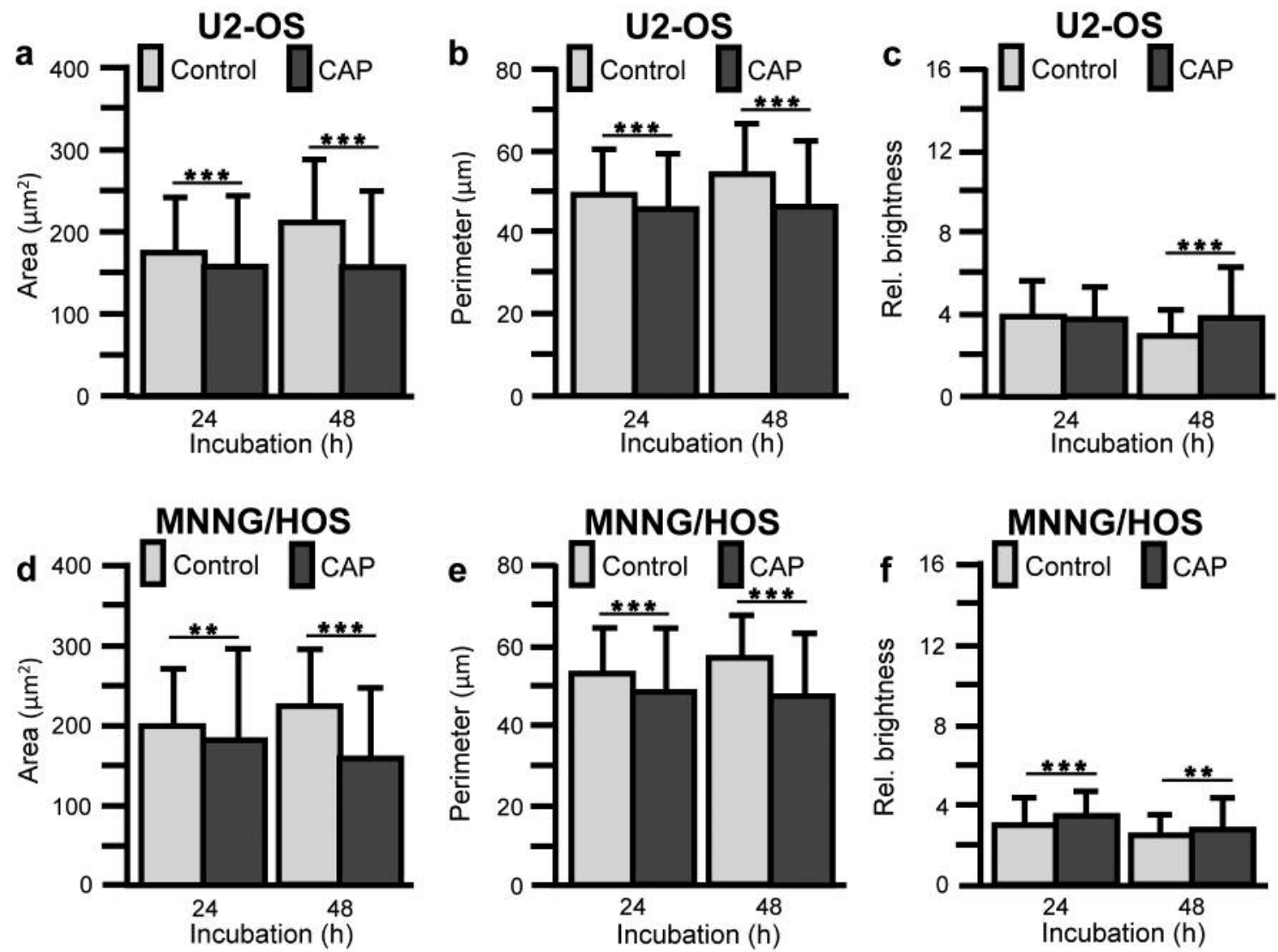

Figure 4. Biostatistical analysis of cold atmospheric plasma (CAP)-induced apoptotic changes of nuclei. 4',6-diamidino-2-phenylindole (DAPI)stained nuclei as depicted in Figure 3b, $d$, f and $h$ were analyzed by the Hybrid Cell Count BZ-H2C module of the BZ II Analyzer software (Keyence). Nuclear morphology in fixed and DAPI-stained U2-OS cells (a-c) and MNNG/HOS cells $(d-f)$ was characterized regarding area (a, $d$ ), perimeter $(b, e)$, and brightness $(c, f)$ of stained nuclei. Data are given as the mean $\pm S D$, statistically analyzed by Student's t-test. Significantly different compared to the control at *p $\leq 0.05, * * \leq 0.01$, and $* * * p \leq 0.001$.

intraoperative CAP treatment of resection surfaces to further reduce the risk for recurrence and metastasis. Questions remain if CAP may represent a mutagenic agent being harmful to healthy structures. To date, little is known about the side-effects of CAP treatment due to relatively scarce in vitro data. The same plasma device has been shown not to induce mutagenic effects after application to the inner membrane hen egg up to a plasma exposure time of $10 \mathrm{~min}$ (11). Nevertheless, potential long-term effects need to be ruled-out in vivo prior to clinical application in patients with OS. This applies particularly to mutagenic and carcinogenic risks. Nevertheless, CAP has been shown to increase endothelial cell proliferation through fibroblast growth factor-2 release and NO production $(20,22,26)$. Because angiogenesis is a key factor in metastasis enhanced by cancer tissue through local cytokine and growth factor release, this risk remains to be further examined.

Our results indicate that CAP may be a novel and promising therapeutic option in OS treatment. Further studies should evaluate individual therapy parameters including treatment intensity, exposure time, and the potential of $\mathrm{CAP} /$ chemotherapy combination therapies. Furthermore, future in vivo studies need to examine the influence of CAP on adjacent tissue structures, tumor volume, invasiveness and metastasis. After further adjustment of CAP-producing devices to clinical needs, this novel technique could significantly expand the therapeutic alternatives in orthopedic oncology.

\section{Acknowledgements}

The Authors thank Anne Brandenburg and Katja Wittig for excellent technical assistance.

\section{References}

1 Fridman G. FG, Gutsol A, Shekhter A, Vasilets V and Fridmann A: Applied plasma medicine. Plasma Process Polym 5: 503-533, 2008. 


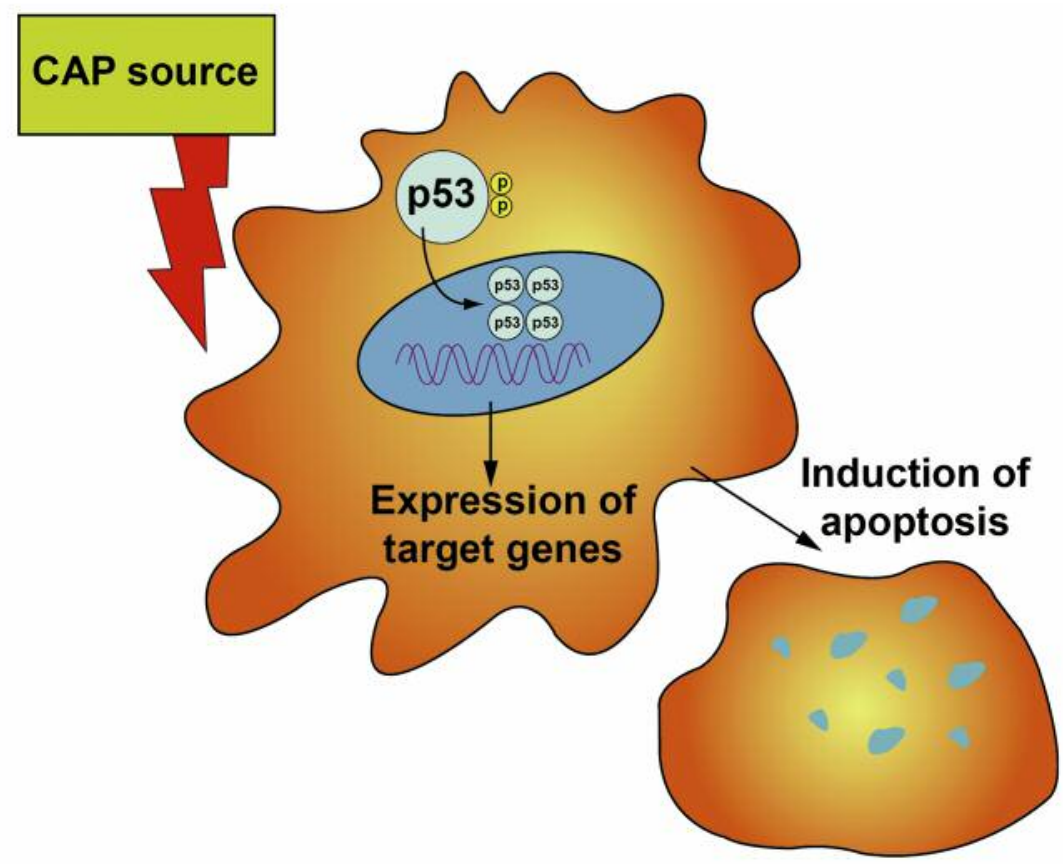

Figure 5. Impact of cold atmospheric plasma (CAP) on osteosarcoma (OS) cell physiology. CAP treatment results in enhanced expression, as well as in enhanced phospho-activation of the apoptotic factor p53. Consequently, induction of apoptosis diminishes the cellular growth rate.

2 Heinlin J, Isbary G, Stolz W, Morfill G, Landthaler M, Shimizu T, Steffes B, Nosenko T, Zimmermann J and Karrer S: Plasma applications in medicine with a special focus on dermatology. $\mathrm{J}$ Eur Acad Dermatol Venereol 25: 1-11, 2011.

3 Kramer A, Bekeschus S, Matthes R, Bender C, Stope MB, Napp M, Lademann O, Lademann J, Weltmann K-D and Schauer F: Cold physical plasmas in the field of hygiene - relevance, significance, and future applications. Plasma Process Polym 12: 1410-1422, 2015.

4 Kramer A, Lademann J, Bender C, Sckell A, Hartmann B, Münch S, Hinz P, Ekkernkamp A, Matthes R, Koban I, Partecke I, Heidecke CD, Masur K, Reuter S, Weltmann KD, Koch S and Assadian O: Suitability of tissue tolerable plasmas (TTP) for the management of chronic wounds. Clinical Plasma Medicine 1: 11-18, 2013.

5 Partecke LI, Evert K, Haugk J, Doering F, Normann L, Diedrich S, Weiss FU, Evert M, Huebner NO, Guenther C, Heidecke CD, Kramer A, Bussiahn R, Weltmann KD, Pati O, Bender C and von Bernstorff W: Tissue tolerable plasma (TTP) induces apoptosis in pancreatic cancer cells in vitro and in vivo. BMC cancer 12: 473, 2012.

6 Weiss M, Gumbel D, Hanschmann EM, Mandelkow R, Gelbrich $\mathrm{N}$, Zimmermann U, Walther R, Ekkernkamp A, Sckell A, Kramer A, Burchardt M, Lillig $\mathrm{CH}$ and Stope MB: Cold atmospheric plasma treatment induces anti-proliferative effects in prostate cancer cells by redox and apoptotic signaling pathways. PloS one 10: e0130350, 2015.

7 Schlegel J, Koritzer J and Boxhammer V: Plasma in cancer treatment. Clinical Plasma Medicine 1: 2-7, 2013.

8 Keidar M, Walk R, Shashurin A, Srinivasan P, Sandler A, Dasgupta S, Ravi R, Guerrero-Preston R and Trink B: Cold plasma selectivity and the possibility of a paradigm shift in cancer therapy. Br J Cancer 105: 1295-1301, 2011.

9 Luetke A, Meyers PA, Lewis I and Juergens H: Osteosarcoma treatment - Where do we stand? A state of the art review. Cancer Treat Rev 40: 523-532, 2014

10 Stope MB, Bradl J, Peters S, Streitborger A, Weiss M, Zimmermann $\mathrm{U}$, Walther $\mathrm{R}$, Lillig $\mathrm{CH}$ and Burchardt $\mathrm{M}$ : Shortened isoforms of the androgen receptor are regulated by the cytoprotective heat-shock protein HSPB1 and the tumorsuppressive microRNA miR-1 in prostate cancer cells. Anticancer Res 33: 4921-4926, 2013.

11 Kluge S BS, Bender C, Benkai H, Sckell A, Below H, Stope MB and Kramer A: Investigating the in vivo mutagenicity of a cold atmospheric pressure argon plasma jet in an HET-MN model. (Unpublished).

12 Koritzer J, Boxhammer V, Schafer A, Shimizu T, Klampfl TG, Li YF, Welz C, Schwenk-Zieger S, Morfill GE, Zimmermann JL and Schlegel J: Restoration of sensitivity in chemo-resistant glioma cells by cold atmospheric plasma. PloS one 8: e64498, 2013.

13 Weiss M, Gumbel D, Gelbrich N, Brandenburg LO, Mandelkow R, Zimmermann U, Ziegler P, Burchardt M and Stope MB: Inhibition of cell growth of the prostate cancer cell model LNCaP by cold atmospheric plasma. In Vivo 29: 611-616, 2015.

14 Pilz M, Holinka J, Vavken P, Marian B and Krepler P: Taurine chloramine induces apoptosis in human osteosarcoma cell lines. J Orthop Res 30: 2046-2051, 2012.

15 Yano S, Miwa S, Kishimoto H, Urata Y, Tazawa H, Kagawa S, Bouvet M, Fujiwara $\mathrm{T}$ and Hoffman RM: Eradication of osteosarcoma by fluorescence-guided surgery with tumor labeling by a killer-reporter adenovirus. J Orthop Res 34: 836-844, 2016. 
16 Barry MA, Behnke CA and Eastman A: Activation of programmed cell death (apoptosis) by cisplatin, other anticancer drugs, toxins and hyperthermia. Biochem Pharmacol 40: 23532362, 1990 .

17 Grossebrummel H, Peter T, Mandelkow R, Weiss M, Muzzio D, Zimmermann U, Walther R, Jensen F, Knabbe C, Zygmunt M, Burchardt M and Stope MB: Cytochrome P450 17A1 inhibitor abiraterone attenuates cellular growth of prostate cancer cells independently from androgen receptor signaling by modulation of oncogenic and apoptotic pathways. Int J Oncol 48: 793-800, 2016.

$18 \mathrm{Hu}$ J, Zhang NA, Wang R, Huang F and Li G: Paclitaxel induces apoptosis and reduces proliferation by targeting epidermal growth factor receptor signaling pathway in oral cavity squamous cell carcinoma. Oncol Lett 10: 2378-2384, 2015.

19 Chen Y, Li M, Li Z, Gao P, Zhou X and Zhang J: Bufalin induces apoptosis in the U2OS human osteosarcoma cell line via triggering the mitochondrial pathway. Mol Med Rep 13: 817$822,2016$.

20 Zhang Z, Shao Z, Xiong L and Yang S: Inhibition of autophagy enhances cisplatin-induced apoptosis in the MG63 human osteosarcoma cell line. Oncol Lett 10: 2941-2946, 2015.

21 Bekeschus S, Kolata J, Winterbourn C, Kramer A, Turner R, Weltmann KD, Broker B and Masur K: Hydrogen peroxide: A central player in physical plasma-induced oxidative stress in human blood cells. Free Radic Res 48: 542-549, 2014.
22 Kalghatgi S, Kelly CM, Cerchar E, Torabi B, Alekseev O, Fridman A, Friedman G and Azizkhan-Clifford J: Effects of nonthermal plasma on mammalian cells. PloS one 6: e16270, 2011.

23 Ren JG, Xia HL, Tian YM, Just T, Cai GP and Dai YR: Expression of telomerase inhibits hydroxyl radical-induced apoptosis in normal telomerase negative human lung fibroblasts. FEBS Lett 488: 133-138, 2001.

24 Arjunan KP and Clyne AM: Non-thermal dielectric barrier discharge plasma induces angiogenesis through reactive oxygen species. J R Soc Interface 9: 1447-157, 2012.

25 Haertel B, von Woedtke T, Weltmann KD and Lindequist U: Non-thermal atmospheric-pressure plasma possible application in wound healing. Biomol Ther (Seoul) 22: 477-490, 2014.

26 Kalghatgi S, Friedman G, Fridman A and Clyne AM: Endothelial cell proliferation is enhanced by low dose non-thermal plasma through fibroblast growth factor-2 release. Ann Biomed Eng 38: 748-757, 2010.
Received August 5, 2016

Revised September 1, 2016

Accepted September 5, 2016 